\title{
A diabetic patient in whom $\mathrm{Hb}$ Weesp was incidentally detected when her $\mathrm{HbA} 1 \mathrm{c}$ level was measured
}

\author{
Tomomi Hatayama $^{1,2} \cdot$ Fumio Umeda ${ }^{2} \cdot$ Teruaki Yamauchi $^{2} \cdot$ Hiroshi Ideguchi $^{3}$
}

Received: 19 March 2019 / Accepted: 25 June 2019 / Published online: 5 July 2019

(c) The Japan Diabetes Society 2019

\begin{abstract}
The level of glycated hemoglobin A1c (HbA1c) is widely used to monitor long-term glycemic control in patients with diabetes mellitus. There are more than 30 methods for measuring HbAlc levels. In recent times, high-performance liquid chromatography (HPLC) has become the most commonly used method in Japan. However, HPLC-based HbA1c level measurements do not accurately reflect glycemic control in the presence of $\mathrm{Hb}$ variants. We report the case of a patient with type 2 diabetes mellitus, who was incidentally found to having an extremely rare $\mathrm{Hb}$ variant. A 69-year-old Japanese female visited our clinic and was diagnosed with diabetes mellitus. Her HbA1c level, which was measured using HPLC at our clinic, could not be determined. DNA sequencing revealed a heterozygous mutation in the $\alpha 1$ globin gene (HBA1: c.301C $>$ T, p.Leu101Phe). $\mathrm{Hb}$ Weesp was detected. Many $\mathrm{Hb}$ variants have been reported; however, to the best of our knowledge, this is only the second report about $\mathrm{Hb}$ Weesp in the world and the first from Japan. Clinicians should consider the possibility of Hb variants in cases in which abnormal elution patterns are detected during the measurement of HbAlc using HPLC.
\end{abstract}

Keywords $\mathrm{HbAlc} \cdot \mathrm{Hb}$ Weesp $\cdot \mathrm{Hb}$ variant $\cdot \mathrm{HPLC}$

\section{Introduction}

The glycated hemoglobin A1c (HbA1c) level is indispensable for diagnosing, treating, and monitoring patients with diabetes mellitus. It reflects the previous 8-12 weeks of glycemic control [1]. There are several methods for measuring $\mathrm{HbA1c}$ levels, including ion-exchange high-performance liquid chromatography (HPLC), boronate-affinity HPLC, immunoassays, and enzyme-based assays. Ion-exchange HPLC is the most commonly used method for measuring $\mathrm{HbA} 1 \mathrm{c}$ levels because it is fast, accurate, and reliable [2].

According to the guidelines developed by the American Diabetes Association in 2009, diabetes mellitus should be

Tomomi Hatayama

hatayama@med.kyushu-u.ac.jp

1 Department of Medicine and Bioregulatory Science, Graduate School of Medical Sciences, Kyushu University, 3-1-1, Maidashi, Higashi-ku, Fukuoka 812-8582, Japan

2 Department of Diabetes, Yukuhashi Central Hospital, 5-5-42, Nishimiyaichi, Yukuhashi, Fukuoka 824-0031, Japan

3 Department of Clinical Laboratory, Fukuoka Sanno Hospital, 3-6-45, Momochihama, Sawara-ku, Fukuoka 814-0001, Japan diagnosed based on HbA1c level measurements [3]. However, there are several technical issues that can interfere with HbA1c assays. Hemoglobin ( $\mathrm{Hb}$ ) variants are one such factor. About $20 \%$ of patients with $\mathrm{Hb}$ variants exhibit clinical symptoms, such as polycythemia, hemolytic anemia, or methemoglobinemia. On the other hand, the other $80 \%$ display no clinical symptoms [4].

Recently, there have been a number of cases in which $\mathrm{Hb}$ variants have been incidentally detected when patients with diabetes mellitus had their HbA1c levels measured. Here, we report the case of a patient with type 2 diabetes mellitus, who was incidentally found to have an extremely rare $\mathrm{Hb}$ variant.

\section{Case}

A 69-year-old Japanese female with a 2-year history of type 2 diabetes mellitus visited our clinic. She had been diagnosed with diabetes mellitus by a previous physician, but had not been treated for a few months. She had lost $6 \mathrm{~kg}$ of weight ( $69 \mathrm{~kg} \rightarrow 63 \mathrm{~kg}$ ) during the last 2 months and visited our clinic to achieve glycemic control. She did not have a family history of diabetes. A physical examination 
showed that her body mass index was $31.1 \mathrm{~kg} / \mathrm{m}^{2}$, and her blood pressure was 156/100 mmHg. Blood tests revealed the following results: white blood cell count: $5100 / \mathrm{mm}^{3}$, $\mathrm{Hb}: 15.2 \mathrm{mg} / \mathrm{dl}$, platelets: $46.6 \times 10^{4} / \mathrm{mm}^{3}$, fasting blood glucose: $136 \mathrm{mg} / \mathrm{dl}$, HbA1c: n.d. (ADAMS A1c HA-8160 analyzer, ver. 4.05; Arkray, Kyoto, Japan). An abnormal peak (arrow) was observed before the HbA1c peak, as shown in Fig. 1a. Figure 1b shows the results of high-resolution ion-exchange HPLC separation of the $\mathrm{Hb}$ components in the patient's hemolysate. An abnormal peak (arrow), which was co-eluted with normal $\mathrm{Hb}(\mathrm{A} 0)$, was detected as a right "shoulder peak".

Next, DNA sequencing of the abnormal $\mathrm{Hb}$ gene was performed. Nucleotide sequencing of exon 3 of the $\alpha 1$ globin gene revealed a heterozygous mutation (from CTC to TTC, arrow) at codon 100, as shown in Fig. 2. This mutation resulted in the replacement of leucine by phenylalanine, and this form of $\mathrm{Hb}$ is known as $\mathrm{Hb}$ Weesp [5, 6].

\section{Discussion}

Herein, we report the case of a Japanese patient with type 2 diabetes mellitus, in whom the $\mathrm{Hb}$ variant $\mathrm{Hb}$ Weesp was incidentally detected when we measured her HbA1c levels using the HA-8160 (ver. 4.05) analyzer. There are more than 30 methods for measuring HbA1c levels [7]. HPLC is the most commonly used method in Japan. HbA1c is used as a marker of long-term glycemic control in patients with diabetes mellitus. We sometimes encounter discrepancies between $\mathrm{HbA} 1 \mathrm{c}$ and blood glucose values. Hb variants can interfere with $\mathrm{HbA} 1 \mathrm{c}$ assays. Therefore, clinicians should always be aware of the possibility of abnormal $\mathrm{Hb}$ variants.

$\mathrm{Hb}$ comprises four polypeptide chains, two $\alpha$ chains and two $\beta$ chains. The major form of $\mathrm{Hb}$ found in healthy adults is $\mathrm{HbA}$. Many $\mathrm{Hb}$ variants exhibit different elution
Fig. 1 a Elution patterns obtained with ion-exchange HPLC using the HA-8160 analyzer (ver. 4.05). An abnormal peak was observed before the HbA1c peak (arrow). b Elution patterns obtained with highresolution ion-exchange HPLC. An abnormal peak, which was co-eluted with normal $\mathrm{Hb}(\mathrm{A} 0)$, was detected as a right shoulder peak (arrow)

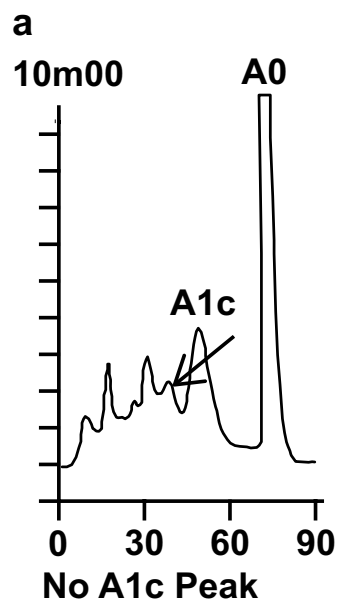

b

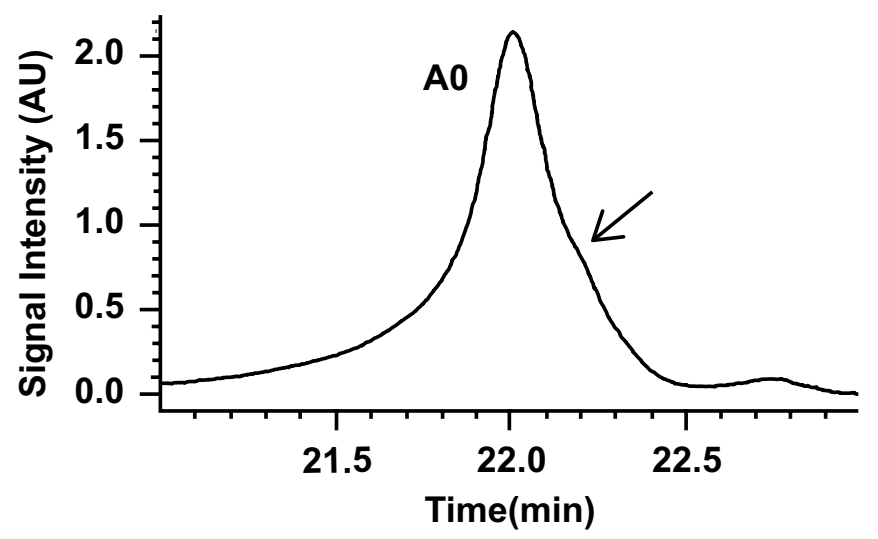

Fig. 2 Identification of the heterozygotic point mutation. At codon 100 of exon 3 of the $\alpha 1$-globin gene, double peaks for $\mathrm{C}$ and $\mathrm{T}$ were detected in the sense chain

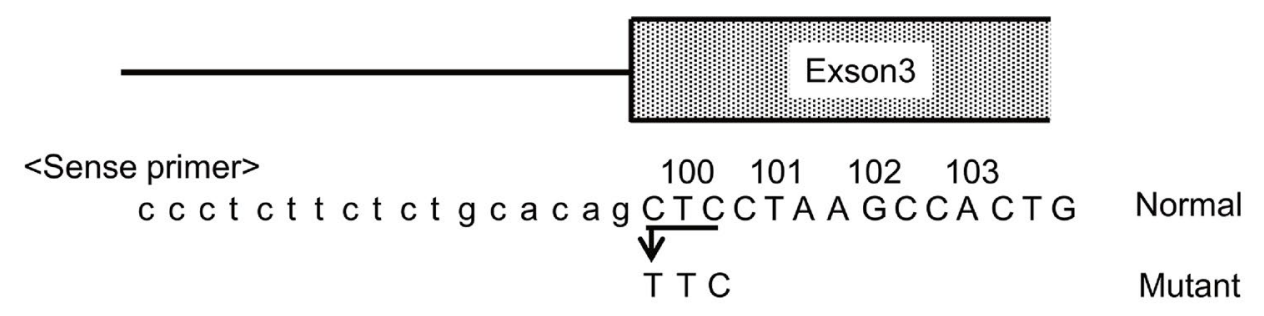

C C CTCTTCTCTGCACAGNTCCTAAGCCACTG

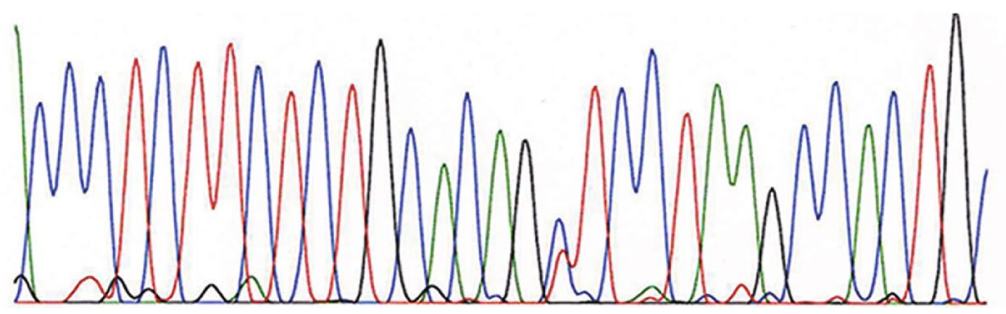


patterns on HPLC. For this reason, HbA1c level measurements are sometimes inaccurate.

$\mathrm{Hb}$ Weesp was first reported in the Netherlands in 2014 [5]. To the best of our knowledge, this is only the second report of $\mathrm{Hb}$ Weesp in the world and the first from Japan. Patients with $\mathrm{Hb}$ Weesp exhibit a heterozygous mutation in the $\alpha 1$-globin gene (HBA1: c.301C > T, p.Leu101Phe). This mutation was demonstrated to be clinically silent [6], and our patient showed no clinical symptoms. Thus, this $\alpha 1$-globin mutation does not result in major changes in the functionality of the $\mathrm{Hb}$ protein.

We analyzed our patient's blood using the HA-8160 analyzer (ver. 4.05). However, her HbAlc level could not be determined due to the presence of abnormal elution patterns. Therefore, we measured her HbAlc level using a different machine, an HA-8160 (ver. 4.22), which was reprogrammed to exclude the abnormal peak, as shown in Fig. 1a. Using this machine, her $\mathrm{HbA} 1 \mathrm{c}$ value was estimated to be $6.0 \%$ (according to the Japan Diabetes Society method). HbA1c values are calculated as the ratio of the area of the $\mathrm{HbA} 1 \mathrm{c}$ peak to the total area of all $\mathrm{Hb}$ peaks. Inaccurate $\mathrm{HbA} 1 \mathrm{c}$ values can be obtained when $\mathrm{Hb}$ variants or their glycated derivatives cannot be separated from $\mathrm{HbA}$ or $\mathrm{HbA} 1 \mathrm{c}$. In such cases, the $\mathrm{Hb}$ variants can be co-eluted with $\mathrm{HbA}$, as shown in Fig. 1b. If the peak indicated by the arrow in Fig. 1a was the peak for the glycated Hb variant, the patient's HbAlc value might have been underestimated. On the other hand, if it was not, it is possible that the patient's HbAlc value was accurate.

More than $1000 \mathrm{Hb}$ variants have been reported worldwide [8], and about $200 \mathrm{Hb}$ variants have been reported in Japan. It is suspected that one in 3000 Japanese have an $\mathrm{Hb}$ variant. The most common $\mathrm{Hb}$ variants found in Japan are $\mathrm{Hb} \mathrm{J}$ Cape Town (an $\alpha$ chain variant, which accounts for $6.6 \%$ of all $\mathrm{Hb}$ variants in Japan) and $\mathrm{Hb}$ Riyadh (a $\beta$ chain variant, 9.2\%) [9]. HbA1c levels are now measured by HPLC in most cases. The HbAlc level has become the most useful and common marker of glycemic control in patients without $\mathrm{Hb}$ variants. In cases involving patients with $\mathrm{Hb}$ variants, $\mathrm{HbA} 1 \mathrm{c}$ levels should be determined using different methods, or other indicators, such as the glycated albumin level, should be used.

Acknowledgements We thank Dr. Takashi Miyazawa for making valuable suggestions and Arkray Co. for their help with the data analysis.

\section{Compliance with ethical standards}

Conflict of interest The authors state that they have no conflicts of interest.

Human rights statement All the procedures were performed in accordance with the Helsinki Declaration of 1964 and later versions.

Informed consent Informed consent was obtained for the publication of this case report.

\section{References}

1. Inoue $\mathrm{K}$, Nakashima $\mathrm{M}$, Masunaga $\mathrm{S}$, Tanigaki N, Hatoyama Y, Nagashio H, Baba T, Nohara M. A case of HbE-Saskatoon and false-low HbA1c value determined by ion-exchange highperformance liquid chromatography (HPLC). Igakukensa. 2018;67(4):575-9.

2. Iizuka K, Mizuno M, Niwa H, Takeda J. A rare case of variant hemoglobin (Hb Yahata) suspected based on inconsistent plasma glucose and HbA1c levels. Intern Med. 2015;54(14):1771-5.

3. International Expert Committee. International Expert Committee report on the role of $\mathrm{A} 1 \mathrm{C}$ assay in the diagnosis of diabetes. Diabetes Care. 2009;32(7):1327-34.

4. Bry L, Chen PC, Sack DB. Effect of hemoglobin variants and chemically modified derivatives on assays for glycohemoglobin. Clin Chem. 2001;47:153-63.

5. Van Zweiten R, Veldthuis M, Delzenne B, Berfhuis J, Groen J, Ait Ichou F, Clifford E, Harteveld CL, Stroobants AK. Hemoglobin analyses in the Netherlands reveal more than 80 different variants including six novel ones. Hemoglobin. 2014;38(1):1-7.

6. Bots M, Stroobants AK, Delzenne B, Soeters MR, de Vries JE, Weykamp CW, Norg RJ, Veldthuis M, van Zwieten R. Two novel haemoglobin variants that affect haemoglobin A1c measurement by ion-exchange chromatography. Clin Chem Lab Med. 2015;53(9):1465-71.

7. John WG. Glycated haemoglobin analysis. Ann Clin Biochem. 1997;34(Pt1):17-31.

8. Server GG: Hb Var: a database of human hemoglobin variants and thalassemias. http://globin.bx.psu.edu/hbvar/menu.html. Accessed 30 Oct 2018

9. Yamashiro Y, Hattori Y. Hemoglobinopathies in Japan: characteristics and comparison with those of other ethnic groups. Rinsho Ketsueki. 2015;56(7):752-9.

Publisher's Note Springer Nature remains neutral with regard to jurisdictional claims in published maps and institutional affiliations. 